\title{
DIVISIONS DISSECTED
}

\section{A Deconstruction of Boston College's "Asian Bubble"}

DANIEL PARK \& YOON-SHIN (CLARA) LEE

ASIAN AMERICAN DISCRIMINATION IS OFTEN ASSOCIATED WITH THE CONCEPT OF THE "ASIAN BUBBLE." THIS DISCRIMINATION IS NO DIFFERENT IN THE BOSTON COLLEGE (BC) COMMUNITY THAN IN MUCH OF SOCIETY AT LARGE. A SERIOUS CONSIDERATION OF THE ASIAN BUBBLE AND THE IMPACT OF THIS LABEL ON THE ASIAN COMMUNITY IS NECESSARY TO OBTAIN A FULL UNDERSTANDING OF THIS COMPLEX ISSUE AND FACILITATE THE SEARCH FOR A PERMANENT SOLUTION. THIS RESEARCH PROJECT IS BASED UPON A SURVEY OF 236 BC STUDENTS THAT WAS CONDUCTED TO GAUGE RESPONDENT PERCEPTIONS OF THE ASIAN COMMUNITY, INVOLVEMENTS ON CAMPUS, AND CONNECTIONS WITH ASIAN AMERICAN IDENTITY. RESULTS OF THE STUDY REVEAL THAT STUDENTS AGREE ABOUT THE EXISTENCE OF NEGATIVE PERCEPTIONS OF THE ASIAN COMMUNITY. NEVERTHELESS, THE STUDY ALSO SHOWS THAT THE ASIAN COMMUNITY IS NOT AS EXCLUSIVE AS MANY PERCEIVE IT TO BE, WHICH OFFERS HOPE FOR FURTHER RESEARCH AND ACTION IN THE FUTURE. 
o

\section{INTRODUCTION}

This paper studies the complex idea of Asian American identity within the context of the Boston College (BC) community. Through this research, we explore various aspects of identity in relation to the Asian American community that exists here at BC. Similar to other AHANA (African, Hispanic, Asian, Native American) students at BC, Asian Americans experience prejudices and stereotyping, but Asian American discrimination is often observed in association with the concept of the "Asian Bubble." It is a phenomenon where Asian students on campus unite and form a unique community, a sub-culture that can seem rather exclusive to students on the outside.

The Asian Bubble is a phenomenon that occurs not only at $\mathrm{BC}$, but also at other schools across the nation. Moreover, this tendency of forming a sub-culture occurs in other ethnicities on campus from other AHANA ethnicities to white students. According to an article written by Timothy Egan published in the New York Times, UC Berkeley student Jonathan $\mathrm{Hu}$ described the separation in ethnic groups as a form of "selective self-segregation," where students of differing ethnicities often do not interact with each other on a regular basis. However, it is interesting that this Asian Bubble is especially stigmatized in comparison to "bubbles" of other ethnicities, given that it is actually white students that form the least diverse racial group. Research conducted by Princeton sociologists Thomas Espenshade and Alexandria Walton Radford shows that white students have the most homogenous friendship groups. ${ }^{.}$A recent poll conducted by Reuters corroborates that information by concluding that $40 \%$ of white Americans and $25 \%$ of non-whites have friends only of the same race. ${ }^{2}$ The negative connotations of the Asian Bubble and the resulting bias against the Asian community on campus only heighten the marginalization of Asian American students. This, in turn, can have a negative impact on individual self-expression and sense of identity because Asian heritage is not perceived as positively as it should be on campus, despite the reality that it constitutes an integral portion of identity for Asian Americans.

\section{SIGNIFICANCE AND PURPOSE}

At $\mathrm{BC}$, a very distinct culture exists, one that students often refer to as the "BC experience." It sets very distinctive expectations of what a BC student should and should not do. Within this larger experience, however, there are also many other sub-cultures that impact individual growth over the course of four years. These sub-cultures are often determined by demographics, such as racial or gender similarities, or extracurricular activities.

Within the Asian community, a large portion of the population is a part of an intercultural organization, whether as a registered member or simply by association. Although past research, performed by Asian Caucus Directors of Policy and Political Initiatives Grace Son and Benjamin Miyamoto, ${ }^{3}$ has shown that Asian American students also participate in other activities and clubs across campus, there is an assumption that they are most, if not solely, involved in these intercultural organizations. This only exacerbates the belief in the community's exclusivity. These negative perceptions not only change the way that students interact with each other, but also influence students' self-perceptions.

On a greater scale, there are also many social norms and stereotypes that revolve around certain racial minorities. These beliefs become dangerous as they are often overgeneralized to the larger population. Even in the university setting, it is noticeable that certain stereotypes are imposed on certain groups. Having these as major identifiers can lead to misrepresentation and marginalization, affecting not only the greater community, but also the individual. Many famous psychologists, such as Eric Erikson, mark college as a crucial time for identity development. Popular beliefs can strongly influence the way students perceive the world around them and their overall satisfaction at the school.

In the wake of recent events at the University of Misouri, Yale, Ithaca, and many more universities across the United

\section{"Similar to other AHANA students at BC, Asian Americans experience prejudices and stereotyping, but Asian American discrimination is often observed in association with the concept of the "Asian Bubble."}




\section{"Students who come from cultures incongruent with the existing culture at a PWI often detach themselves from their culture of origin and adopt the values, norms, and assumptions of the existing dominant culture in order to find success."}

States, many AHANA students have called for policy reform at BC, but before that is done, it is important to understand how institutionalized racism can affect the individual and the larger community, in this case, the Asian American community. This study undertakes a deeper look at more individual and personal differences that may exist within the community. By assessing inter/intra group differences, a better understanding of this particular group, as a whole, can be ascertained. Overall, the research should be able to provide important insights and identify issues specifically pertinent for the Asian American community, such as formation of identity within the context of a predominantly white institution (PWI).

\section{LITERATURE REVIEW}

A review of the existing literature has revealed several interesting insights into Asian American identity and community. The insights and relevant information can be grouped into several categories: the Role of Ethnic Organizations, the Significance and the Effects of Diversity, and the Effect of Predispositions on Asian American Students.

In general, first year AHANA students at PWIs have been shown to experience a significantly weaker sense of belonging than first year white students. ${ }^{4}$ Students who come from cultures incongruent with the existing culture at a PWI often detach themselves from their culture of origin and adopt the values, norms, and assumptions of the existing dominant culture in order to find success. ${ }^{5}$ This is especially significant for Asian American and Black students, as they report the most negative assessments of the environment at PWIs, according to data from the National Survey of Student Engagement. ${ }^{6}$ Research shows that such a result is likely due to some of the stereotypes surrounding both ethnic groups, with Asian American students experiencing pressures that they are academically superior and Black students experiencing the assumption that they are academically inferior.?
Ethnic organizations have been shown to aid in the transition to college, providing AHANA students with an essential component of cultural validation and familiarity, while also serving as a means to advocacy and cultural expression. ${ }^{8}$ The ethnic organizations on campus can also help such students break down the overwhelming unfamiliarity of the university into smaller sub-cultures, making the transition to a PWI much easier. ${ }^{9}$ This compartmentalization of the university is especially significant for students who have "[traversed] a long cultural distance" to come to the university, because integration into a sub-culture on campus has been shown to increase the probability of a student's successful immersion in and adjustment to college. ${ }^{\text {Io }}$ Finally, research conducted on Black students by Harper and Quaye also shows that participation in these ethnic organizations improves cross-cultural communication skills, advocacy for marginalized populations, expression of identity, and the pursuit of social justice. ${ }^{\text {II }}$ While this information refers specifically to Black students, it maintains relevance for Asian Americans because research has indicated that AHANA students do often share common struggles. ${ }^{12}$

Literature on the importance of diversity sheds light on the struggle faced by Asian Americans at PWIs. The marginalization of AHANA students at PWIs is well documented and discussed, with success at college being strongly linked to the sense of belonging a student feels on campus. ${ }^{13}$ White students have consistently reported more faculty and resource availability, alongside the highest overall satisfaction with the campus racial climate. ${ }^{14}$ Moreover, out of 574 first and third year students surveyed at a large mid-Atlantic university, white students reported only limited discrimination, together with an apparent ignorance of the prejudice faced by other minority groups. ${ }^{15}$ Diversity on campus is a crucial part of ensuring all parties are equally included, and perhaps more importantly, fostering positive race relations. Many students, especially at schools such as BC, come from racially homogenous 
backgrounds that do not adequately prepare them to deal with the diversity they have never previously experienced. ${ }^{16}$ Thus, fostering positive race relations is often difficult for many students to do because of their predispositions that steer them towards certain behaviors and paths in college, an element that will be discussed further in the following paragraph. ${ }^{17}$ Moreover, alongside individual commitment to diversity, research has shown strong benefits associated with an institutional commitment to diversity. ${ }^{18}$ An institutional commitment to diversity will significantly improve race relations on campus and overcoming barriers, but it must be done in the right way. Research shows that institutional commitment must manifest itself through provision of educational information on interracial friendships and through support of diverse student interaction. ${ }^{19}$ The diversity on campus needs to operate through the development of interracial friendship in a close, interpersonal environment in order to explicitly support marginalized students. ${ }^{20}$

Predispositions are attitudes and mindsets ingrained within individuals that influence them in certain directions. In the case of Asian American identity, predispositions affect the individual actions of groups of students, which in turn can affect the overall culture of an institution. ${ }^{2 \mathrm{I}}$ The culture of an institution may then impact the identity of Asian American students, who arrive with certain predispositions. Literature indicates the importance of accentuation theory, which theorizes that students' predispositions entering college are reinforced as students select certain activities and peer groups. ${ }^{22}$ Thus, those who have experience with diversity and recognize its importance will likely accentuate that value by selecting "courses, peers, and activities that will strengthen their initial inclinations." ${ }^{23}$ This theory is especially important to consider at a PWI such as BC that has many students, faculties, and administrative staffs from homogenous backgrounds. ${ }^{24}$ These predispositions also impact the racial tension on campus through a fear-induced anxiety of interacting with diverse groups which prevents students from interacting confidently and meaningfully. ${ }^{25} \mathrm{~A}$ reduction of said anxiety is therefore integral to increasing inter-ethnic interaction, and by consequence all essential feelings of belonging students feel at school.

The literature offers interesting implications for the Asian American community in relation to the larger population, whether in private institutions or more casual settings.
These implications establish an interesting frame of reference with which to study the BC community. Through the study of Asian American identity and community within the context of a specific institution, this study seeks to integrate academic credibility into future conversations about the Asian community, the various perceptions and connotations of the term Asian Bubble, and the idea of Asian American identity within the context of BC. These findings and information will initiate the change in perceptions of the Asian American community at BC, open up opportunities for further research, advocacy, and even inspiration for Asian American communities outside of the context of BC.

\section{METHODS}

For our research, a survey was distributed to and completed by $236 \mathrm{BC}$ students, both those on campus and those abroad during the Fall 2015 semester, almost all of whom identified as Asian or Asian American, or had one parent of Asian descent. Of the participant pool, $36 \%$ identified as Chinese, $32 \%$ as Korean, $5 \%$ as Taiwanese, $5 \%$ as Indian/ South Asian, 4\% as Filipino, and 9\% were of mixed ethnic descent. $56.9 \%$ were from the Morrisey School of Arts and Sciences, $24.6 \%$ from the Carroll School of Management, I0.6\% from the Connell School of Nursing, and the remaining $7.7 \%$ studied in the Lynch School of Education. Aside from basic demographic questions such as race and graduation year, the survey contained a diverse array of questions to help us collect as much data as possible, including multiple choice, free response, and Likert scale. The questions were intended to gather information on three topics: I) Perception of the Asian community; 2) In-

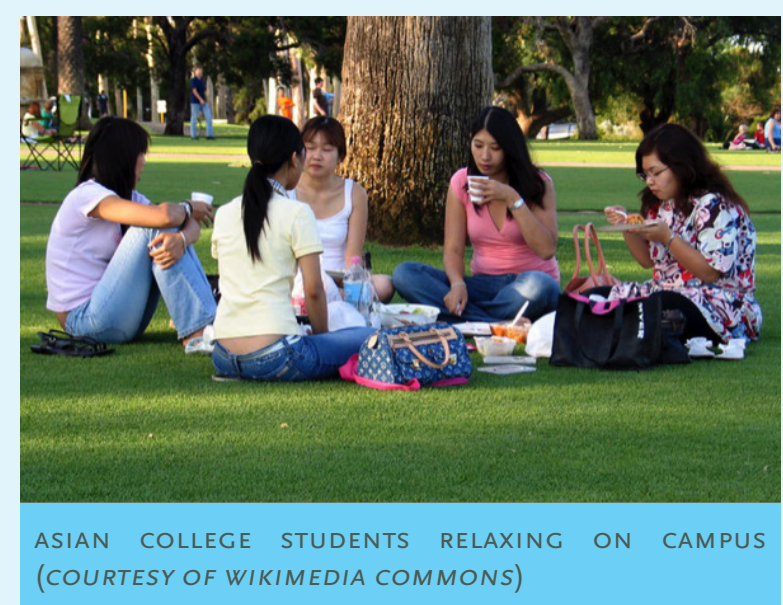


volvement on campus; 3) Perception of "Asian" identity. Also, several non-Asian students filled out the survey. Their responses were noted, as they could provide useful opinions; however, they were not included in the overall analysis of the survey.

The survey was split into two portions: identity and community. The identity section mainly consisted of involvement in high school and college activities for freshmen, sophomores, juniors, and seniors, respectively. They were also asked questions on how strongly they identified with their ethnicity, using a Likert scale. The question, "If you were on the phone with someone you never met, how would you describe yourself in one sentence?" has answers coded into 8 different categories: physical, personality traits, characteristic values, activities, interests, labels/roles, cultural/ethnic, and miscellaneous. The last of the 8 was coded as a $\circ$. The second part consisted of varying questions and statements about beliefs regarding the Asian Bubble and perceptions of the community, which were also all measured by a Likert scale. A question on the perception of the Asian American community was also asked. The survey questioned respondents: "In your own words, how do you define the Asian Bubble?” If a response had a negative perception, it was coded as -I, if neutral or mixed, it was coded as o, if it had a positive perception, it was coded as I.

Moreover, depending on whether the participants indicated whether they were freshmen or not, a separate Freshman Survey, slightly different from the Sophomore-Senior survey, was provided. Freshmen may have a different perspective on the campus community, and their experiences or lack thereof can prevent them from providing reliable answers to some of the questions tailored for the upperclassmen, such as: "How has the Asian community impacted your personal development?" Therefore, they were asked questions about their past involvement in high school, and questions about their perception of the existing Asian community at BC. Questions about identity and beliefs about the Asian Bubble remained the same. Like the previous survey, this survey mainly utilized a Likert scale for a majority of its questions, such as "Do you believe that the Asian Bubble will impact your experience at BC over the course of your four years?" Depending on the question, strength of agreement or negative/positive attitude was measured.

The survey was distributed to the BC community utilizing several mediums. Under the campus club Asian

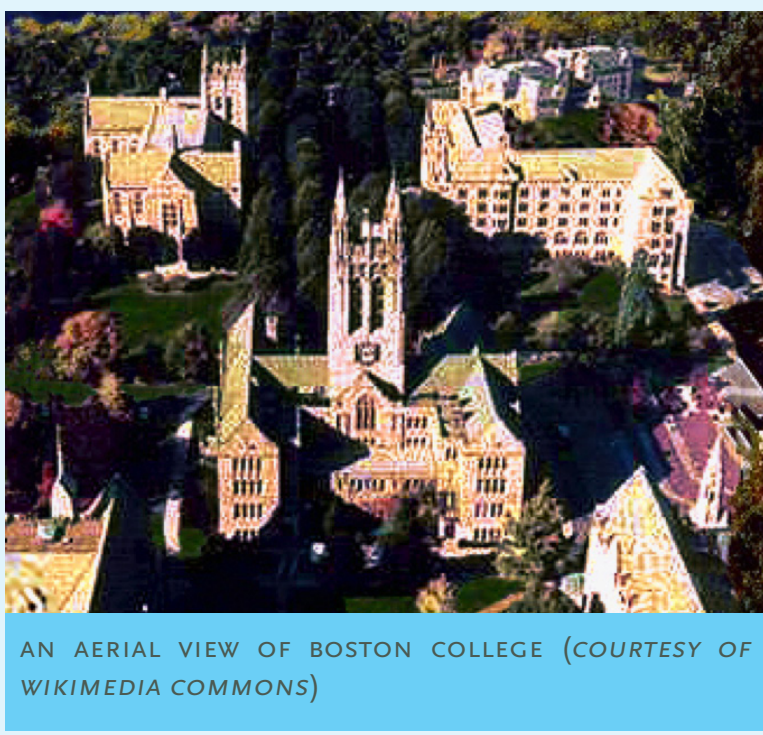

Caucus, the Asian Caucus Facebook page, e-mail list, and events could be used to continually advertise the survey and the associated raffle prizes to a wider audience. Moreover, the Thea Bowman AHANA Intercultural Center (BAIC) staff assisted with the distribution of the survey. The BAIC staff has access to an e-mail group that includes all the Asian students on campus, and the email that BAIC staff members sent to the group on our behalf directly resulted in many more responses. The last form of advertisement, but by no means the least, was simple word of mouth. The survey was released to the public in late September, and upon closing of the survey on November I5, a comprehensive analysis of the data received was conducted.

\section{RESULTS}

In the survey, a section of the questions, for both freshmen and upperclassmen, was measured by a Likert Scale. Depending on the question, the scale measured the degree of agreement or the degree of a positive/negative attitude, shown in Figure I and 2. Freshmen were asked different questions in a similar manner as explained above.

The freshman mode ranged between 3 and 4 . With a standard deviation of I.339, the question regarding involvement in the Asian community in high school had the highest standard deviation. There was also a negative correlation of -0.127 between the belief in the existence of the Asian Bubble and integration into the Asian community during 


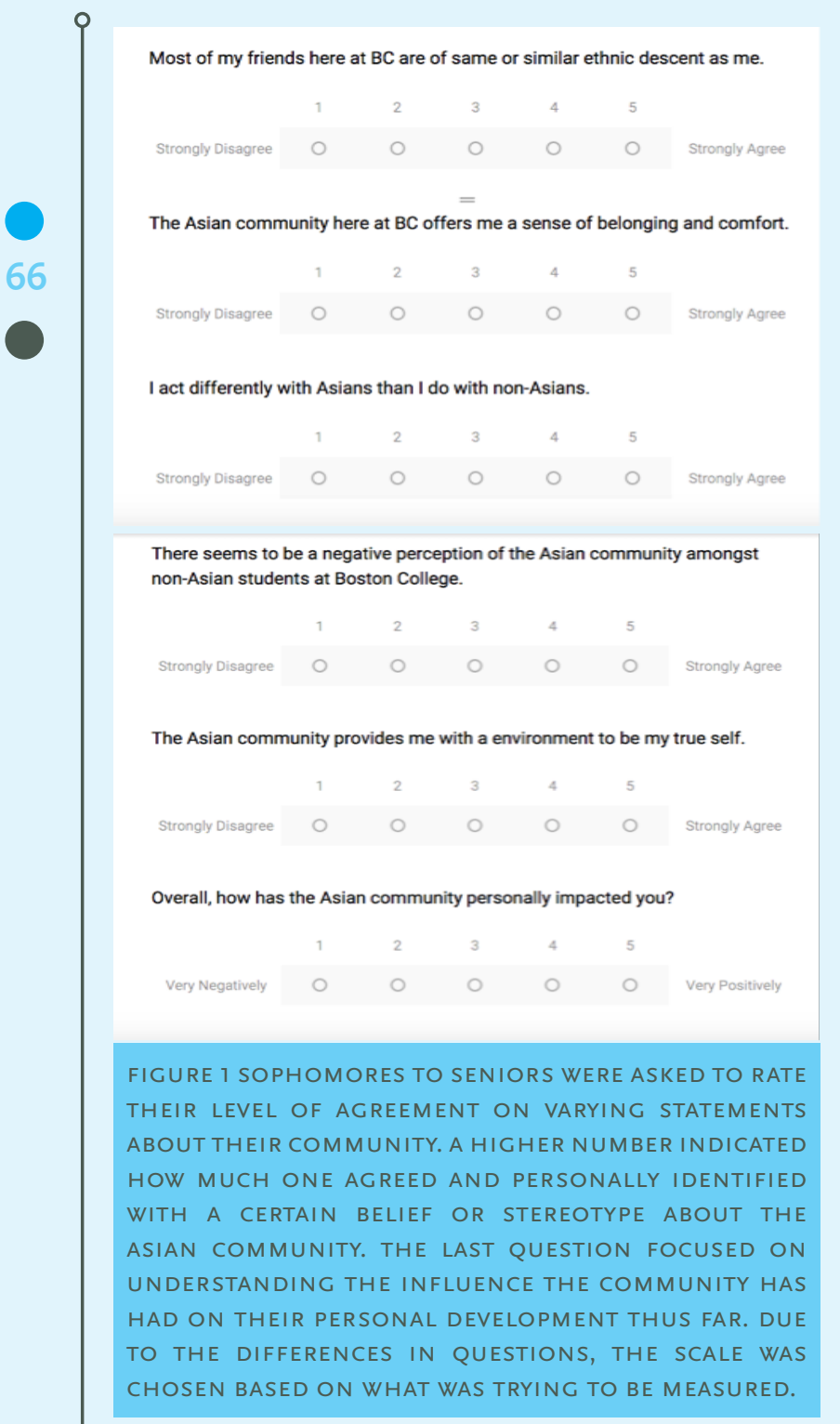

high school. The correlation between the expected impact of the Asian Bubble on one's experience and expectations of the Asian community had a correlation of 0.247 .

For sophomores and seniors, the statement, "Most of my friends here at $\mathrm{BC}$ are of same or similar ethnic descent as me," had the largest, standard deviation of I.355, whereas the question of "Overall, how has the Asian community personally impacted you?" had the lowest standard devia- tion of 0.824 . This question also had the lowest range of 3, as no one answered I for this particular question. The statement, "There seems to be a negative perception of the Asian community amongst the non-Asian students at BC," had a median of 4 , while other statements and questions all had a median of 3 .

Correlation between the impact of the Asian community on their "BC experience," and the definition of the Asian Bubble was 0.236 . When the statistic of the definition of the Asian Bubble is replaced with that of the perception of the Asian Bubble, the correlation rises to .438 . The correlation between how much an individual identified with the Asian community at $\mathrm{BC}$ and their perception of the Asian Bubble was 0.426 .
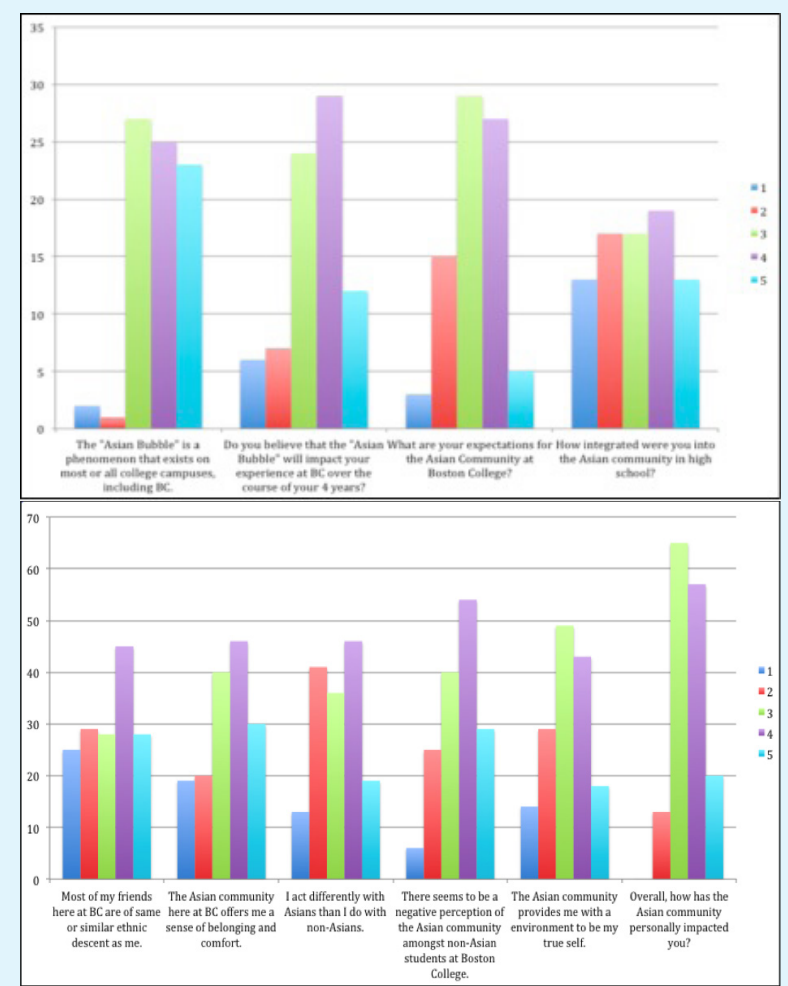

FIGURE 2 DISTRIBUTION OF ANSWERS FOR FRESHMEN (TOP) AND SOPHOMORES AND SENIORS (BOTTOM). ALL OF THE QUESTIONS WERE MEASURED BASED ON WHAT WAS CONSIDERED THE MOST APPROPRIATE MEASURE/SCALE. FOR THE FRESHMEN, THE QUESTION "WHAT ARE YOUR EXPECTATIONS OF THE BOSTON COLLEGE COMMUNITY?" WAS MEASURED ON A LIKERT SCALE OF 'VERY EXCLUSIVE' TO 'VERY INCLUSIVE.' 
Between identity and how strongly one identified with his or her Asian heritage, the correlations were -0.106 and 0.Ioo, for freshmen and sophomores, juniors, and seniors, respectively. It was also shown that freshmen had a greater tendency to give a negative definition for the Asian Bubble, at a mean of - 0.244 , compared to their sophomore, junior, and senior counterparts, at -o.I88.

\section{DISCUSSION}

Based on the results, three important findings about the intersection of identity and community were identified.

First of all, our research showed that the Asian American community is not as exclusive as the perception of the Asian Bubble would suggest. Freshmen entering BC showed much variation in past involvement in the Asian community, and sophomores, juniors, and seniors indicated that many have friends of different ethnic descent, with the largest variation. For involvement, freshmen were shown to be more involved in service, athletics, and academics during high school. As for sophomores, juniors and seniors, the top three involvements were cultural, service, and academics, which were all close in number. Unlike what was predicted, identity and ethnic heritage were shown to have a very low correlation. Individuals were more likely to identify themselves with personal traits than anything else, regardless of their graduation year. It disproves the idea that Asian Americans exclusively involve themselves with those who are ethnically similar to them. Out-group differences and visible characteristics are therefore more likely to be emphasized and shared. Although individually, participants were more likely to use personal characteristics, their general view of the Asian Bubble was still negative.

One statistic that was particularly interesting was how many students agreed that there was a negative perception of the Asian community at BC. It had the highest mean of 3.48 and mode of 4 , in comparison to other statements and questions. Within the group, beliefs and characteristics are more determined by expectations of the greater community rather than individual contributions. Expectations, even in larger society, play a huge role in determining the ways that individuals think, both about the community and about themselves. This may also contribute to the exclusivity that is perceived. These negative perceptions may discourage individuals from interacting with those outside of their community.
Curiously, there was not a strong correlation between several categories hypothesized to show a strong significance. For example, the correlation between an individual's perception of the Asian Bubble and how much an individual identifies with the Asian community was 0.426 , which was lower than expected going into the initial analysis of the dataset. This surprisingly weak relationship also continues into the analysis of correlation between other factors such as the impact of the Asian community on one's "BC experience" and one's definition of the Asian Bubble. Initially, it was expected that if one believed the Asian community impacted their "BC experience" in a positive manner, they would also have a more positive definition of the Asian Bubble. However, that correlation only came out to be 0.236 . A possible cause for this is that there are students who filled out the survey and indicated a positive perception of the Asian Bubble, are not actively involved in the community, thus lowering the correlations. If true, then it could show that the negative perceptions of the Asian community are not as pronounced as many within the community believe.

Lastly, an interesting difference between the freshman perception and the upperclassman perception of the Asian community was noticed. When analyzing the results of the question "In your own words, how do you define the Asian Bubble?" it was notable that the freshmen had a more negative perception than the upperclassmen. Using the perception code of negative: -I, neutral: $O$, and positive: I, freshmen had an average perception of -0.244 , while the upperclassmen had an average of -o.I88. This may be due to one of two reasons: I) Groupthink affects upperclassmen who are a part of the Asian community to respond

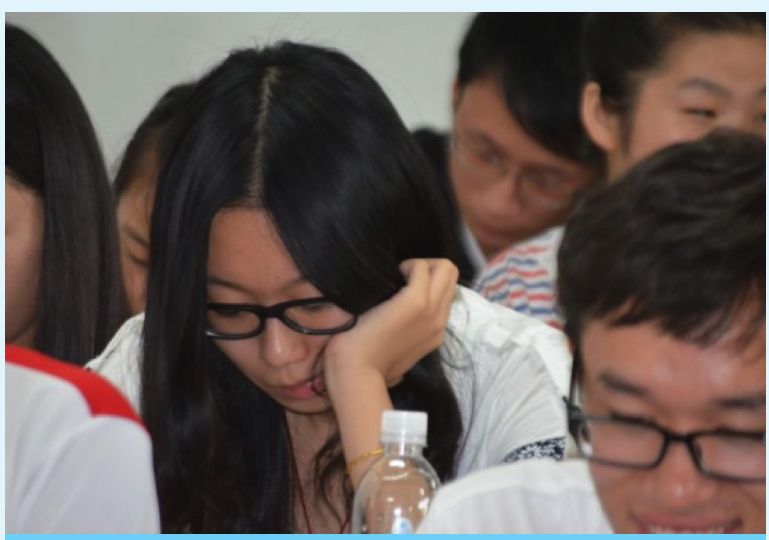

ASIAN STUDENTS IN CLASS (SOURCE: PUBLICDOMAINPICTURES) 


\section{"The hope is to foster a community of people who support the growth and development of each individual, while also igniting the flame for Asian American advocacy."}

positively, or 2) Directly experiencing the Asian community contradicts the negative perceptions surrounding the community, leading upperclassmen to have more positive perceptions.

These results can all be linked to the concept of Asian American Identity. The Asian community as a whole is an agglomeration of unique individuals that are all seeking to find a sense of identity and belonging on campus. In coming to BC, Asian Americans will likely feel naturally marginalized, given the lack of diversity present in many areas of the school. Moreover, the presence of a tightly knit Asian community offers a familiarity that is key for a student's sense of belonging and ultimate sense of identity as individuals. Thus, despite most of the information and findings relating to the Asian community as a whole, it is still pertinent for our main concern of the Asian American student on an individual level. The hope is to foster a community of people who support the growth and development of each individual while also igniting the flame for Asian American advocacy. In attempting to study the community through an objective lens, we desire to integrate academic credibility into conversations about the Asian community, the various perceptions and connotations of the Asian Bubble, and the idea of Asian American identity within the context of BC.

\section{LIMITATIONS}

There were many limitations in both data collection and data analysis. As the survey was conducted on campus with a limited amount of time, our sample was a self-selected, convenience sample. Although around $25 \%$ of the Asian population at $\mathrm{BC}$ participated in the study, that quarter may have been representative of only a few specific characteristics of the larger population, therefore cannot be generalized to all Asian BC students. With the collection method that was used, the survey was more likely to reach a certain group of individuals within the greater population. Students more involved in the Thea Bowman AHANA Intercultural Center, more likely to check email, or those who are members of Asian intercultural clubs had a higher probability of being exposed to the survey at one point during the two months time span.

As with most surveys, there are also threats of self-report and response bias. It is difficult to truly surmise whether the responses received were honest or whether individuals interpreted our questions in different manners. Due to individual differences, answers to certain questions may have been different, leading to a different analysis of our data. Although a disclaimer to the survey was included, in electronic form, people may have been more hesitant about being completely candid with their responses. Also, being an Asian American study, it may have changed answers or elicited varying responses to certain questions. Individuals may have been more inclined to use personal characteristics or other descriptors, rather than ethnic or racial ones in their answers, knowing that all participants were of the same race.

For the freshmen data that was collected, there was also an issue of time. Based on the time at which freshmen completed the survey, answers may have differed. If filled out closer to the end of the two months, freshmen may have been exposed to the Asian community quite a bit by that time, thus altering their perceptions about the community. Providing this survey to incoming freshmen at orientation or when they were accepted to BC would have been a more ideal situation to rid any confounding variables.

Lastly, with the topic chosen and the consequent research done, it is difficult to make concrete conclusions about this topic. More research would need to be done on each specific subtopic in order to get a clearer understanding of the actual results. This survey would need to be repeated longitudinally to see the actual long-term effects of the Asian community on an individual.

\section{FUTURE RESEARCH}

It is important for this study to be continued in the future in order to assess the true long-term impact of one's perception of the community on one's identity. 
Longitudinally, this study would be more valuable in understanding how perceptions and behaviors develop over time. However, within this study, there are many other ideas that can be more deeply analyzed. Being an explorative study, there are also many subtopics that may have not been looked at in detail. The interactions within the community and whether or not they are reflective of what was found within this research could be further explored. Also, conducting the research on other schools' campuses can potentially shed light on how these subcultures may differ at universities.

In the future, it is also important to consider both outgroup and in-group differences in the research, both of which play key roles in how certain beliefs are developed concerning our own community. This does not only ring true for societal ideas and norms, but also for subtle beliefs amidst the community. By looking at ways in which others perceive other communities, it is also possible to look at how the Asian community is perceived. Especially in a time and age that is changing so rapidly, it is crucial to evaluate how in-group differences are changing. Studying how certain beliefs may affect actual behavior may provide insightful conclusions as well.

Perceptions of others can also largely impact one's beliefs. Understanding how fellow members view not only the community but also those on the outside can provide a new perspective on existing ideas. Although the topics studied mostly pertain to Asian American students, it would also be helpful to assess students of other races. Conducting studies on the sense of identity for other AHANA ethnicities would be especially useful. Not only can such research provide useful insight for students of other races, but it may also identify where common struggles exist for all AHANA students, thus providing a stronger foundation for social unity and advocacy efforts on campus. Furthermore, it would help recognize and differentiate various ethnicities and the issues they are facing. This will prevent the oversimplification of all AHANA issues as one single question.

\section{ENDNOTES}

I. Park, "The Asian College Bubble," 20I5.

2. Dunsmuir, "Many Americans Have No Friends of Another

Race," 2013.

3. Son and Miyamoto, "PPI Asian Caucus Student Involvement Survey," 2015.

4. Alvarez et al., "Examining Sense of Belonging Among FirstYear Undergraduates From Different Racial/Ethnic Groups," 2007; Bowman et al., "Extending Notions of Campus Climate and Diversity to Students' Transition to College," 2008; Museus, "The Role of Ethnic Student Organizations in Fostering African American and Asian American Students' Cultural Adjustment and Membership at Predominantly White Institutions," 2008.

5. Museus, "The Role of Ethnic Student Organizations," 2008

6. Ibid.

7. Ibid.; Ancis, Sedlacek, and Mohr, "Student Perceptions of Campus Cultural Climate by Race," 2000 .

8. Museus, "The Role of Ethnic Student Organizations," 2008 9. Ibid.

Io. Ibid.

II. Harper and Quaye, "Student Organizations as Venues for Black Identity Expression and Development among African American Male Student Leaders," 2007.

I2. Museus, "The Role of Ethnic Student Organizations," 2008; Alvarez et al., "Examining Sense of Belonging," 2007.

I3. Alvarez et al., "Examining Sense of Belonging," 2007

I4. Ancis, Sedlacek, and Mohr, "Student Perceptions of Campus Cultural Climate by Race," 2000.

I5. Ibid.

I6. Bowman et al., "Extending Notions of Campus Climate and Diversity to Students' Transition to College," 2008

I7. Ibid.; Saenz, Ngai, and Hurtado, "Factors Influencing Positive Interactions Across Race for African American, Asian American, Latino, and White College Students," 2006.

I8. Antonio, "Diversity and the Influence of Friendship Groups in College," 200I; Alvarez et al., "Examining Sense of Belonging," 2007; Saenz, Ngai, and Hurtado, "Factors Influencing Positive Interactions Across Race," 2006

I9. Antonio, "Diversity and the Influence of Friendship Groups in College," 200I.

20. Ibid.

21. Bowman et al., "Extending Notions of Campus Climate and Diversity to Students' Transition to College," 2008.

22. Ibid.

23. Ibid.

24. Ibid.

25. Ibid. 


\section{REFERENCES}

Alvarez, Patty, Dawn R. Johnson, Karen Kurotsuchi Inkelas, Matthew Soldner, Jeannie Brown Leonard, Heather T. Rowan-Kenyon, and Susan D. Longerbeam. "Examining Sense of Belonging Among First-Year Undergraduates From Different Racial/Ethnic Groups." Journal of College Student Development 48, no. 5 (September 27, 2007): 52542. doi: I0.1353/csd.2007.0054.

Ancis, Julie R., William E. Sedlacek, and Jonathan J. Mohr. "Student Perceptions of Campus Cultural Climate by Race." Journal of Counseling \& Development 78, no. 2 (April I, 2000): I80-85. doi: I0.1002/j.I556-6676.2000. tbo2576.x.

Antonio, Anthony Lising. "Diversity and the Influence of Friendship Groups in College." The Review of Higher Education 25, no. I (September I, 200I): 63-89. doi: I0.1353/rhe.200I.00I3.

Bowman, Nicholas A., Sylvia Hurtado, Angela M. Locks, and Leticia Oseguera. "Extending Notions of Campus Climate and Diversity to Students' Transition to College." The Review of Higher Education 3I, no. 3 (March I0, 2008): $257-85$.

Dunsmuir, Lindsay. "Many Americans Have No Friends of Another Race: Poll." Reuters, August 8, 20I3. http://www.reuters.com/article/us-usa-poll-raceidUSBRE97704320130808.

Harper, Shaun, and Stephen Quaye. "Student Organizations as Venues for Black Identity Expression and Development among African American Male Student Leaders." Journal of Student College Development 48 , no. 2 (March 2007). http://repository.upenn.edu/cgi/ viewcontent.cgi?article $=$ II70\&context=gse_pubs.

Museus, Samuel D. "The Role of Ethnic Student Organizations in Fostering African American and Asian American Students' Cultural Adjustment and Membership at Predominantly White Institutions." Journal of College Student Development 49, no. 6 (2008): 568-86. doi: I0.1353/csd.0.0039.

Park, Julie J. "The Asian College Bubble: Self-Segregation or Something More?" The Huffington Post. Accessed December 5, 2015. http://www.huffingtonpost.com/juliej-park/self-segregation_b_3785384.html.
Saenz, Victor B., Hoi Ning Ngai, and Sylvia Hurtado. "Factors Influencing Positive Interactions Across Race for African American, Asian American, Latino, and White College Students." Research in Higher Education 48, no. I (May 23, 2006): I-38. doi: 10.1007/sini62-006-9026-3.

Son, and Miyamoto. "PPI Asian Caucus Student Involvement Survey." Asian Caucus, 20I5. 